\title{
Platelet to lymphocyte ratio in differentiation of benign and malignant thyroid nodules
}

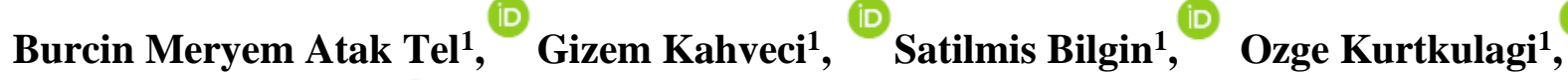 \\ Mehmet Ali Kosekli² \\ ${ }^{I}$ Department of Internal Medicine. Bolu Abant Izzet Baysal University, Medical School, Bolu, Turkey \\ ${ }^{2}$ Department of Gastroenterology, Bolu Abant Izzet Baysal University, Medical School, Bolu, Turkey
}

\begin{abstract}
Aim: Differentiation of thyroid nodules, either as benign or malignant, is a real diagnostic challenge. Inflammation has an important role in development of the malignancy. Therefore, inflammatory markers are associated with malignant thyroid nodules. Platelet /lymphocyte ratio (PLR) is also one of the novel inflammatory indices derived from hemogram tests. We hypothesized whether PLR was associated with malignant thyroid nodules. For this purpose, we compared PLR levels of the patients with benign thyroid nodules to the PLR of the subjects with malignant nodules.
\end{abstract}

Methods: The subjects who visited outpatient internal medicine clinics of our institution with a diagnosis of thyroid nodule were enrolled to the present retrospective study. According to the examination of the fine needle aspiration cytology (FNAC) specimen of the nodules, patients grouped into benign or malignant nodule groups. PLR of groups were compared.

Results: Median PLR values of the benign and malignant thyroid nodule groups were 106 (48-432) \% and 119 $(48-365) \%$, respectively $(p=0.001)$. PLR value higher than $106 \%$ has $69 \%$ sensitivity and $51 \%$ specificity in detecting malignant nodules (AUC: $0.59, p=0.001,95 \%$ CI: 0.54-0.65). PLR was positively correlated with TSH level $(r=0.10, p=0.34)$.

Conclusion: We suggest that elevated PLR could be an additional tool to differentiate malignant thyroid nodules from benign ones in supportive of sonography, scintigraphy and cytology.

Keywords: Platelet lymphocyte ratio, thyroid nodule, malign, benign, inflammation.

$\triangle$ Dr. Burcin Meryem Atak Tel

Department of Internal Medicine, Bolu Abant Izzet

Baysal University, Hospital, Bolu, Turkey

E-mail: burcinatak@hotmail.com

Received: 2021-02-18

Accepted: 2021-03-13 / Published online: 2021-04-01

\section{Introduction}

Differentiation of thyroid nodules, either as benign or malignant, is a real diagnostic challenge. Since a considerable amount of thyroid nodules are malignant, differentiation of these nodules is crucial. Nodules may develop in thyroid gland especially in iodine deficient areas of the world and its prevalence in women may reach up to $5 \%$ [1]. Detection rate of thyroid nodules by ultrasound scanning is a bit higher as $20 \%$ [2].

Inflammation has an important role in development of the malignancy [3]. Therefore, inflammatory markers are associated with malignant thyroid nodules. For instance, creactive protein (CRP) and novel inflammatory markers, such as, mean platelet volume, red cell distribution width and neutrophil/lymphocyte ratio are elevated in malignant thyroid nodules [4-7]. 
Platelet /lymphocyte ratio (PLR) is also one of the novel inflammatory indices derived from hemogram tests. It has substantial diagnostic and prognostic value in certain conditions. PLR has been correlated with glycated hemoglobin (HbA1c) levels in subjects with type 2 diabetes mellitus [8]. Moreover, authors suggested PLR as a prognostic factor of survival in colorectal cancer patients [9].

As other cancer types and type 2 diabetes mellitus, malignant thyroid nodules are associated with inflammation. Therefore, we hypothesized whether PLR was associated with malignant thyroid nodules. For this purpose, we compared PLR levels of the patients with benign thyroid nodules to the PLR of the subjects with malignant nodules.

\section{Materials and methods}

The subjects who visited outpatient internal medicine clinics of our institution between May 2018 and December 2020 with a diagnosis of thyroid nodule were enrolled to the present retrospective study. Ethical approval obtained from institutional ethics committee (approval number: 2021-26). The study was conducted in accordance with the principles of the Declaration of Helsinki. All patients and the institution were informed about the study and their written consents were obtained. According to the cytological examination of the fine needle aspiration biopsy (FNAB) specimen of the nodules, patients grouped into benign or malignant nodule groups.

Age, sex, thyroid stimulating hormone (TSH), white blood cell count (WBC), hemoglobin $(\mathrm{Hb})$, hematocrit (Htc), lymphocyte count (lym), platelet count (PLT) were obtained from the laboratory tests of the participants that held before FNAB. Exclusion criteria were as follows; inflammatory conditions including thyroiditis, recent infection, type 2 diabetes mellitus, cancer, hematologic conditions that may affect platelet count, use of medicines that may interfere with hematopoiesis or thrombocyte functions (i.e. corticosteroids, acetyl salicylate). Hemogram tests were held with Abbott Cell-Dyn 3700 automatic analyzer device (Abbott Laboratories, Abbott Park, IL, USA). TSH assay was done with original kits of the manufacturer in Abbott Architect i2000SR device (Abbott Laboratories, Abbott Park, IL, USA).

Statistical analysis conducted by SPSS software (SPSS15.0; SPSS Inc., Chicago, IL, USA). Fitness of the measurable variables to normal distribution was evaluated by KolmogorovSmirnov test. Variables with normal distribution were compared with student $t$ test and expressed as mean \pm Standard Deviation. Variables without normal distribution were compared with Mann Whitney $\mathrm{u}$ test and expressed as median (minimum-maximum). Comparison of the frequency data was held with $\mathrm{X}^{2}$ test and these data were expressed as percentage. Significance level is considered as a $\mathrm{p}$ value lower than 0.05 in all statistical tests.

\section{Results}

After application of exclusion criteria, remaining 443 patients were enrolled to the study. Benign thyroid nodule group was consisted of 207, while malignant thyroid nodule group was consisted of 236 subjects.

Mean ages of the benign and malignant thyroid nodule groups were $43.1 \pm 7.4$ years and $44.6 \pm$ 11.6 years, respectively $(p=0.12)$.

Forty nine (24\%) of the subjects were male and $158(76 \%)$ were female in benign thyroid nodule group while 55 (23\%) were male and $181(77 \%)$ were female in malignant thyroid nodule group. Gender was not statistically different among study groups, either $(p=0.93)$. 
The $\mathrm{Hb} \quad(p=0.49)$, Htc $(p=0.07)$, WBC $(p=0.08), \mathrm{Plt}(p=0.76)$ and TSH $(p=0.16)$ of the benign and malignant thyroid nodule groups were not statistically different.

Median PLR values of the benign and malignant thyroid nodule groups were 106 (48432) $\%$ and 119 (48-365) \%, respectively. PLR value of the malignant thyroid nodule group was significantly higher than that of the benign thyroid nodule group $(p=0.001)$.

A ROC analysis revealed that a PLR value higher than $106 \%$ has $69 \%$ sensitivity and $51 \%$ specificity in detecting malignant nodules (AUC: 0.59, $p=0.001$, 95\% CI: 0.54-0.65). Figure 1 shows the ROC curve of PLR in detecting malignant thyroid nodules.

In Pearson's correlation analysis, PLR was positively correlated with TSH level $(r=0.10$, $p=0.34$ ). Figure 2 shows the correlation between PLR and TSH.

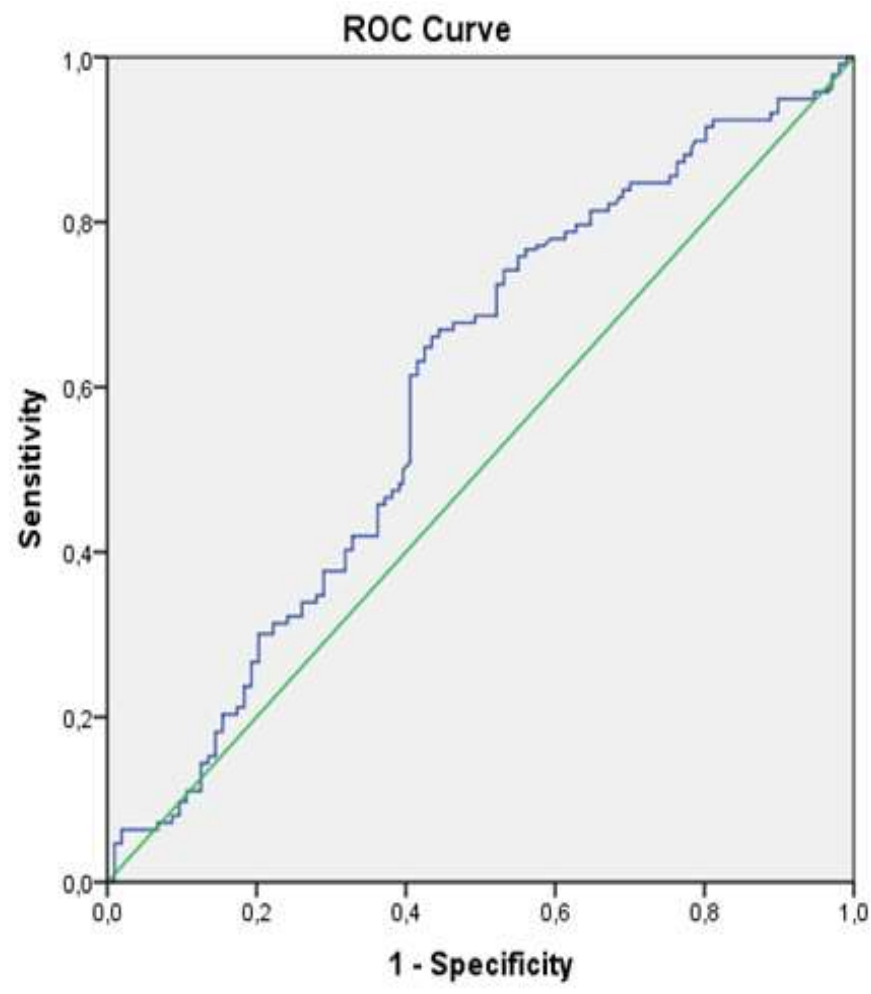

Diagonal segments are produced by ties.

Figure 1. The ROC curve of PLR in detecting malignant nodules in thyroid gland.

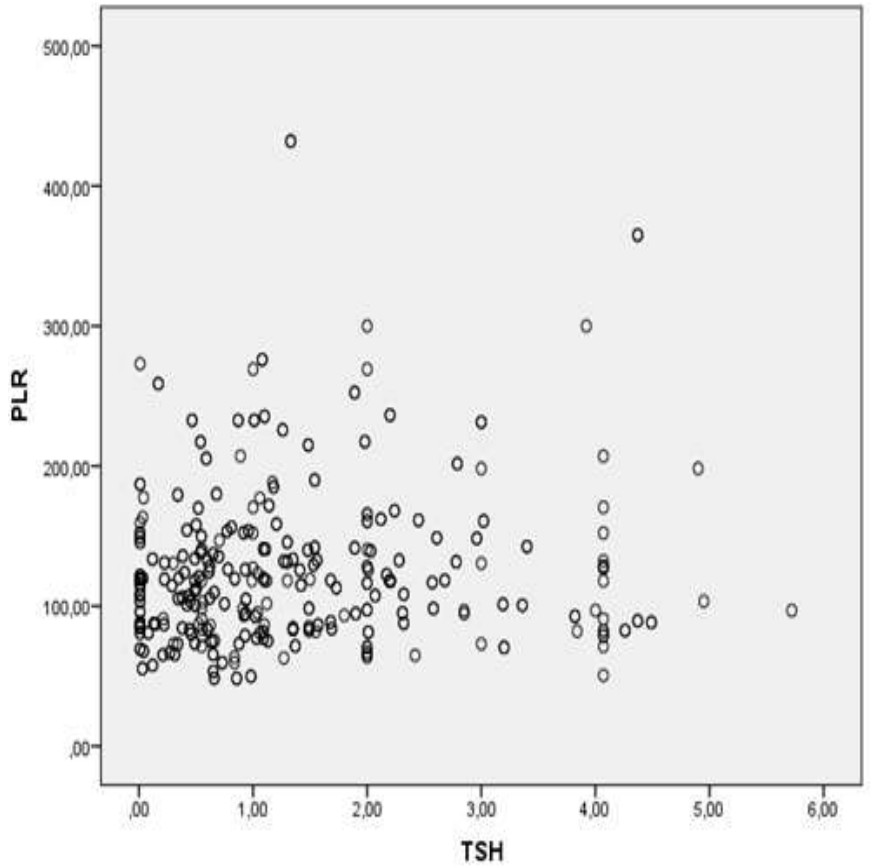

Figure 2. Correlation between TSH and PLR.

\section{Discussion}

Present study demonstrated that PLR of the subjects with malignant thyroid nodule is significantly elevated compared to the PLR of the subjects with benign thyroid nodule. Another important outcome of present study is moderate sensitivity and specificity of the PLR in detecting malignant nodules in thyroid gland. Finally, significant positive correlation between TSH and PLR was revealed by present work.

Recent studies pointed out the diagnostic and prognostic role of PLR in various inflammatory conditions. Atak et al reported that PLR was associated with type 2 diabetes mellitus and correlated with HbA1c [8]. PLR levels of the subjects with lower extremity deep venous thrombosis were significantly higher than the PLR levels of the subjects without thrombosis [10]. Moreover, patients with Covid-19 have increased PLR levels compared to the healthy controls [11]. In addition, elevated PLR was suggested to be a predictor of early mechanical ventilation requirement in subjects with Covid- 
19 [12]. Both, type 2 diabetes mellitus, venous thrombosis and Covid-19 infection are inflammatory conditions as malignant thyroid nodules. Therefore, the findings of present study, which revealed elevated PLR levels in patients with malignant thyroid nodules, are consisted with literature.

The role of inflammation in cancer development is pivotal $[13,14]$. PLR is a novel inflammatory marker. Therefore, cancer is also associated with increased PLR values. A study from Poland reported that PLR was correlated with survival in patients with endometrium cancer [15]. High PLR levels were correlated with worse overall survival in oral squamous cell carcinoma patients [16]. Preoperative PLR level has been proposed as an independent prognostic factor of survival in rectal cancer [17]. Authors reported that PLR level in pretreatment period could be a prognostic index in patients with non-small cell lung cancer [18]. The PLR of the patients with recurrent ovarian cancer are higher than the PLR of healthy subjects [19]. Malignancy attracts inflammatory cells and causes an increase in circulating inflammatory mediators. Malignant thyroid nodules are also causing such inflammatory burden. As shown in present study, PLR levels of these subjects are increased compared to the PLR levels of the patients with benign thyroid nodules.

Thyroid nodules are associated with inflammation. Authors found that the prevalence of thyroid nodules is higher in subjects with hyperhomocysteinemia, another condition that precedes inflammation [20]. Sit et al reported that mean platelet volume and neutrophil/lymphocyte ratios were predictors of malignancy in thyroid nodules [6,7]. Moreover, erythrocyte distribution width has been introduced as a predictor of malignant thyroid nodules in patients with nodular goiter [5].
Both, mean platelet volume, neutrophil/lymphocyte ratio and erythrocyte distribution width are inflammatory markers of hemogram tests, as the PLR. Therefore, similar elevation in PLR noticed in malignant nodules compared to benign nodules in present study.

Sonographic characteristics for suspicious malignancy in thyroid nodules include speculated edges, vertical shape, microcalcification and hypoechogenicity, which all have diagnostic sensitivity less than 50\% [21]. Another tool for differentiating malignant and benign nodules is scintigraphy. Cold nodules in thyroid scintigraphy images are more likely to be malignant. However, nearly 3 of every 4 cold nodules is not malignant and malignancy detected in cytology of the $6 \%$ of hot nodules [22]. Gold standard method of the diagnosis of thyroid nodules as benign or malignant is fine needle aspiration cytology (FNAC), however, false negative and false positive results of FNAC have been reported around 10\% [23]. Therefore, elevated PLR in malignant thyroid nodules compared to benign nodules could be a useful adjunctive test in discrimination of these nodules.

Relatively small study population and retrospective design of the work are two main limitations of our study. However, to the bet of our knowledge, this is the first study in literature reported elevated PLR levels in patients with malignant thyroid nodules.

In conclusion, we suggest that elevated PLR could be an additional tool to differentiate malignant thyroid nodules from benign ones in supportive of sonography, scintigraphy and cytology.

Funding: The author(s) received no financial support for the research, authorship, and/or publication of this article. 
Conflict of Interest: The authors declare that they have no conflict of interest.

Ethical statement: The study was approved by the Ethics committee of Bolu Abant Izzet Baysal University (Date and Decision no: 2021-26)

\section{Open Access Statement}

This is an open access journal which means that all content is freely available without charge to the user or his/her institution under the terms of the Creative Commons Attribution NonCommercial License

(http://creativecommons.org/licenses/bync/4.0). Users are allowed to read, download, copy, distribute, print, search, or link to the full texts of the articles, without asking prior permission from the publisher or the author.

\section{References}

[1]Tunbridge WM, Evered DC, Hall R et al. The spectrum of thyroid disease in a community: the Whickham survey. Clin Endocrinol. 1977; 7 (6): 481-93.

[2]Guth S, Theune U, Aberle J et al. Very high prevalence of thyroid nodules detected by high frequency $(13 \mathrm{MHz})$ ultrasound examination. Eur J Clin Invest. 2009; 39 (8): 699-706.

[3]Allavena P, Sica A, Solinas G et al. The inflammatory micro-environment in tumor progression: the role of tumor-associated macrophages. Crit Rev Oncol Hematol. 2008; 66 (1): 1-9.

[4]Ozmen S, Timur O, Calik I et al. Neutrophillymphocyte ratio (NLR) and plateletlymphocyte ratio (PLR) may be superior to C-reactive protein (CRP) for predicting the occurrence of differentiated thyroid cancer. Endocr Reg. 2017; 51 (3): 131-36.

[5]Aktas G, Sit M, Karagoz I et al. Could Red Cell Distribution Width be a Marker of
Thyroid Cancer? J Coll Physicians Surg Pak. 2017; 27 (9): 556-58.

[6]Sit M, Aktas G, Erkol H et al. Neutrophil to Lymphocyte Ratio is Useful in Differentiation of Malign and Benign Thyroid Nodules. P R Health Sci J. 2019; 38 (1): 60-63.

[7]Sit M, Aktas G, Ozer B et al. Mean Platelet Volume: an overlooked herald of malignant thyroid nodules. Acta Clin Croat. 2019; 58 (3): 417-20.

[8]Atak B, Aktas G, Duman TT et al. Diabetes control could through platelet-tolymphocyte ratio in hemograms. Rev Assoc Med Bras. 2019; 65 (1): 38-42.

[9]Kwon HC, Kim SH, Oh SY et al. Clinical significance of preoperative neutrophillymphocyte versus platelet-lymphocyte ratio in patients with operable colorectal cancer. Biomarkers. 2012; 17 (3): 216-22.

[10] Wen H, Chen Y. The predictive value of platelet to lymphocyte ratio and D-dimer to fibrinogen ratio combined with WELLS score on lower extremity deep vein thrombosis in young patients with cerebral hemorrhage. Neurol Sci. 2021. doi: 10.1007/s10072-020-05007-y

[11]Eslamijouybari M, Heydari K, Maleki I et al. Neutrophil-to-Lymphocyte and Platelet-toLymphocyte Ratios in COVID-19 Patients and Control Group and Relationship with Disease Prognosis. Caspian J Intern Med. 2020; 11 (Suppl 1): 531-35.

[12] Nair PR, Maitra S, Ray BR et al. Neutrophilto-lymphocyte Ratio and Platelet-tolymphocyte Ratio as Predictors of the Early Requirement of Mechanical Ventilation in COVID-19 Patients. Ind J Crit Care Med. 2020; 24 (11): 1143-44.

[13] Coussens LM, Werb Z. Inflammation and cancer. Nature. 2002; 420 (6917): 860-67. 
[14]Grivennikov SI, Greten FR, Karin M. Immunity, inflammation, and cancer. Cell. 2010; 140 (6): 883-99.

[15] Muzykiewicz KP, Iwanska E, Janeczek M et al. The analysis of the prognostic value of the neutrophil/ lymphocyte ratio and the platelet/lymphocyte ratio among advanced endometrial cancer patients. Ginekol Pol. 2021;92(1):16-23.

[16]Zhuang Z, Li Y, Hong Y et al. A novel prognostic Score based on systemic inflammatory Biomarkers for Patients with oral squamous Cell carcinoma. Oral Dis. 2021. doi: 10.1111/odi.13774.

[17] Wang P, Wang Z, Liu Y et al. Prognostic value of platelet-associated biomarkers in rectal cancer patients received neoadjuvant chemoradiation: A retrospective study. Cancer Radiother. 2021;S1278-3218(20): 30342-345.

[18]Liu K, Jiang G, Fang $N$ et al. Platelet/lymphocyte ratio is a significant prognostic factor for targeted therapy in patients with EGFR-mutated non-small-cell lung cancer. J Int Med Res. 2020; 48 (12): 300060520980205.

[19] Wang N, Li C, Yang Y et al. The Usage of Platelet/Lymphocyte Ratio, Carbohydrate Antigen 125 Combined with Magnetic Resonance Diffusion Weighted Imaging in Diagnosis of Recurrent Ovarian Cancer and Neuropathic Pain. World Neurosurg. 2020;S1878-8750(20): 32502-X.

[20] Pan Q, Wang Y, Wang G. The Association Between Hyperhomocysteinemia and Thyroid Nodule Prevalence in an Adult Population. Metab Syndr Relat Disord. 2020;18(8):368-72.

[21] Moon WJ, Jung SL, Lee JH et al. Benign and malignant thyroid nodules: US differentiation--multicenter retrospective study. Radiology. 2008; 247 (3): 762-70.
[22] Kountakis SE, Skoulas IG, Maillard AA. The radiologic work-up in thyroid surgery: fine-needle biopsy versus scintigraphy and ultrasound. Ear Nose Throat J. 2002; 81 (3): 151-54.

[23] Maia FF, Zantut-Wittmann DE. Thyroid nodule management: clinical, ultrasound and cytopathological parameters for predicting malignancy. Clinics (Sao Paulo). 2012; 67 (8): 945-54. 